DOI: http://dx.doi.org/10.11606/issn.1984-4867.v27i2p323-341

\title{
Luz, Câmera... Segmentação: uma proposta de turismo cinematográfico para a cidade de Niterói-RJ
}

\author{
Lights, Camera... Segmentation: a proposal of film tourism for the city of Niterói-RJ \\ Luces, Cámara... Segmentación: una propuesta de turismo de cine para la ciudad de \\ Niterói-RJ
}

Rômulo Duarte ${ }^{1}$

Ari da Silva Fonseca Filho

\begin{abstract}
Resumo
O turismo cinematográfico é um segmento do mercado turístico, no qual o turista viaja motivado a conhecer um local após tê-lo visto em alguma produção audiovisual, em especial, no cinema. Essas produções podem ser filmes minisséries, seriados ou as novelas. Nesse sentido, o objetivo geral do artigo é apresentar o potencial da cidade de Niterói-RJ para o desenvolvimento do turismo cinematográfico. Os objetivos específicos são: destacar a relação entre o turismo e o audiovisual; apresentar a cidade de Niterói como um destino cinematográfico; e construir um catálogo de locações, que contemple os atrativos que expressam a identidade da cidade. A metodologia consistiu de um levantamento de atrativos turísticos da cidade; levantamento de informações sobre estes; e visitas aos locais para a realização do registro fotográfico e observação sobre possíveis locações para produções audiovisuais. Como principal resultado dessa pesquisa, tem-se a catalogação dos atrativos da cidade organizados na forma de um catálogo de locações, cujo objetivo é apresentar o potencial para produção audiovisual que a cidade tem.
\end{abstract}

Palavras-chave: Turismo Cinematográfico; Turismo Cultural; Niterói; Locações de filmes; Audiovisual.

\begin{abstract}
Film tourism is a tourist market segment in which the tourist or 'set-jetter' travels to know a site after seeing it onscreen, often after seeing it in a movie.These productions are commonly cinematographic films, miniseries, TV shows or soap operas. Accordingly, the objective of this research is to present the potential for the development of the film tourism in the city of Niterói, Rio de Janeiro. The specific objectives are to highlight the relationship between tourism and audiovisual productions; to present the city of Niterói as a film destination and

\footnotetext{
${ }^{1}$ Mestrando em Turismo pelo Programa de Pós-Graduação em Turismo da Universidade Federal Fluminense (PPGTUR-UFF). Graduação em Turismo pela Universidade Federal Fluminense (UFF). Bolsista Pesquisador em Turismo na Fundação Casa de Rui Barbosa (FCRB/MinC). Rio de Janeiro, Rio de Janeiro, Brasil. E-mail: romuloduarteoliveira@gmail.com

${ }^{2}$ Mestre e Doutor pela Faculdade de Educação da Universidade de São Paulo (FEUSP-USP). Bacharel em Turismo pela Universidade Estadual de Ponta Grossa (UEPG). Professor Adjunto II da Faculdade de Turismo e Hotelaria da Universidade Federal Fluminense (UFF). Rio de Janeiro, Rio de Janeiro, Brasil. E-mail: arifonseca@id.uff.br
} 
build a locations catalog that features the touristic attractions that represent the identity of the city. The research methodology consists of research about the tourist attractions of the city; collected information of those places; and photographs of them displaying their potential as possible locations for audiovisual productions.The main result of this research is the cataloging of the city's touristic attractions organized as a locations' catalog, which aimed to present the potential for the city's audiovisual production.

Keywords: Film Tourism; Cultural Tourism; Niterói; Film locations; Audiovisual.

\section{Resumen}

El turismo de cine es un segmento del mercado turístico, en el turista viaja motivado para conocer un lugar después de haberlo visto en cualquier producción audiovisual, especialmente en una película. Estas producciones pueden ser miniserie, películas, comedias o telenovelas. En este sentido, el objetivo general del artículo es presentar el potencial de la ciudad de Niterói-RJ para el desarrollo del turismo cinematográfico. Los objetivos específicos son: poner de relieve la relación entre el turismo y audiovisual; presentar la ciudad de Niterói como destino de cine; y construir un catálogo de ubicaciones, cubriendo los atractivos que expresan la identidad de la ciudad. La metodología consistió en una encuesta de las atracciones turísticas de la ciudad; la recopilación de información sobre ellas; y el sitio de visita para llevar a cabo el registro fotográfico y hacer comentarios sobre posibles ubicaciones para producciones audiovisuales. El principal resultado de esta investigación, ha sido la catalogación de atracciones de la ciudad organizados en forma de un catálogo de localizaciones, cuyo objetivo es dar a conocer el potencial de la producción audiovisual que tiene la ciudad.

Palabras clave: Turismo de Cine; Turismo Cultural; Niterói; Localizaciones de películas; Audiovisual.

\section{Considerações Iniciais}

A segmentação de mercadona área de turismo é uma tendência mundial e o turismo cinematográfico se desponta como um segmento emergente, devido ao sucesso na divulgação e promoção de um destino turístico por meio da produção e exibição de filmes ou qualquer outro produto audiovisual. Assim, o processo de segmentação de mercado “[...] consiste em um grande grupo que é identificado a partir de suas preferências, poder de compra, localização geográfica, atitudes de compra e hábitos de compra similares” (KOTLER, 2000, p.278).

No turismo cinematográfico os turistas são conhecidos como set-jetters, termo designado para os viajantes motivados a conhecer locais que serviram como locação para alguma produção audiovisual, seja ela um filme, série de TV ou até mesmo uma novela (NASCIMENTO, 2009). 
Dessa forma, optou-se por estudar o potencial audiovisual que a cidade de Niterói-RJ possui para este segmento com a proposta de criação de um catálogo a partir dos atrativos que a cidade tem, delimitados pela Prefeitura da cidade, que possam ser usados em produções audiovisuais e propõe-se que este documento sirva como um banco de dados para produtores, diretores e demais interessados em locações do município.

A relevância da produção deste artigo é visível na medida em que este segmento é uma tendência no turismo e observa-se um potencial ainda não desenvolvido na cidade de Niterói. O objeto de estudo está localizado na região sudeste, a $13 \mathrm{~km}$ da cidade do Rio de Janeiro, possui atrativos naturais e culturais diversos que poderiam ser levantados para a criação de um catálogo cuja finalidade é a de mostrar as possibilidades existentes nesses locais para produções audiovisuais.

Para a comunidade local da cidade, o desenvolvimento de novas produções audiovisuais e, consequentemente, do segmento turístico em questão podem ser uma futura oportunidade de emprego, pois quando existem produções audiovisuais na cidade, mão-de-obra local é requisitada pela produção. Sendo assim, é interessante perceber o quanto a comunidade local pode ganhar com esse segmento. A viabilidade pode ser vista a partir da facilidade em coletar os dados de análise, sendo possível encontrar as informações em diversos sites pela Internet, até mesmo com as próprias entidades políticas ou pelas entidades responsáveis por alguns desses atrativos.

O turismo cinematográfico é um campo de estudo recente no meio acadêmico. Esse fato devese porque esse tipo de segmentação é mais novo que outras segmentações e somente há pouco tempo estão sendo desenvolvidos estudos para classifica-la e avaliar sua importância para os destinos turísticos. Tendo em vista esse pensamento, levantou-se o seguinte questionamento: em que medida o turismo realizado na cidade pode ser diversificado com a proposta do turismo cinematográfico, diante do seu potencial para o desenvolvimento de novas produções audiovisuais e a utilização das produções que já foram realizadas, sendo estes atrativos turísticos intangíveis do município?

Partindo desse questionamento, os seguintes pressupostos foram levantados: a cidade de Niterói possui potencial para este segmento, porém ele ainda não é desenvolvido na cidade e supõe-se que algumas das produções que são feitas aqui não são suficientemente expressivas para gerar fluxo turístico para a cidade ou são vendidas como a cidade do Rio de Janeiro ou 
não se sabe se essas produções geram movimento turístico em virtude da falta de informações nesse aspecto. Entende-se que a formatação do segmento na cidade poderá aumentar o fluxo de turistas.

O objetivo geral deste estudo é destacar o potencial do turismo cinematográfico para a cidade de Niterói, destacando algumas locações estratégicas que possam demarcar a identidade do município, bem como o desenvolvimento turístico local. Os objetivos específicos são: realizar um estudo sobre a relação turismo e cinema com a finalidade de se conceituar o tema no mundo e no Brasil, entendendo esse segmento como relevante para o desenvolvimento de localidades turísticas;apresentar a cidade de Niterói como um destino audiovisual do Estado; e finalmente, construir um catálogo de locações que possa servir como base de dados de informações dos atrativos que contribua para futura captação de produções audiovisuais e o consequente desenvolvimento do turismo cinematográfico na cidade.

A escassez de referencial teórico sobre o turismo cinematográfico em Niterói fez com que a metodologia do presente artigo seja classificada como exploratória. Segundo Ada Dencker (1998) esse perfil de pesquisavisa à familiarização com o fenômeno ou conseguir nova compreensão deste. Foi a primeira vez que uma pesquisa acadêmica para esse segmento foi realizada na cidade de Niterói com o objetivo de localizar e catalogar, dentro das regiões turísticas da cidade, os atrativos naturais e/ou culturais que podem servir ou que já serviram como locação para produções audiovisuais e estimular o turismo cinematográfico para a cidade.

O início da pesquisa foi com base no levantamento bibliográfico com o tema turismo cinematográfico. Foram estudados autores, artigos científicos, documentos oficiais que abordavam os temas citados. Essas informações foram úteis para construção teórica do projeto de pesquisa, a partir dos conceitos trazidos pelos autores. Ada Dencker (1998) afirma que toda a pesquisa requer uma fase preliminar de levantamento e revisão da literatura existente para elaboração conceitual e definição dos marcos teóricos.

A pesquisa de campo consistiu em um registro fotográfico feito nos principais atrativos da cidade de Niterói, com base em um estudo de demanda feito pela Universidade Federal Fluminense em parceria com a Neltur, cujo objetivo foi a caracterização do fluxo e da demanda turística do destino Niterói (NELTUR, 2011), identificando o perfil do turista que visita a cidade. Portanto, é entendido que os atrativos citados pelos turistas na pesquisa são 
aqueles que retratam a identidade de Niterói, logo, os atrativos de maior potencial para o segmento estudado.

Finalmente, o presente artigo foi estruturado da seguinte forma: em um primeiro momento foi feita uma abordagem teórica dos conceitos de turismo cultural e turismo cinematográfico, em seguida, transpõe-se a cidade de Niterói para dentro do contex to do audiovisual, a partir da descrição do processo de criação do catálogo de locações para a cidade.

\section{Turismo Cinematográfico e sua Vertente Cultural}

Antes de abordar o turismo cinematográfico é necessário um primeiro entendimento acerca do turismo cultural e para tal é apresentada uma breve definição trazida pelo Ministério do Turismo que o define como um segmento que:

[...] compreende as atividades turísticas relacionadas à vivência do conjunto de elementos significativos do patrimônio histórico e cultural e dos eventos culturais, valorizando e promovendo os bens materiais e imateriais da cultura (BRASIL, 2010, p.15).

O turismo cultural como segmento percussor do turismo possui algumas tipologias específicas que surgiram em virtude de uma demanda exigida a partir das diferentes formas de expressão da cultura que geraram uma motivação diferente nos turistas (BRASIL, 2010, p. 17). É o caso do turismo cinematográfico, segmento derivado a partir do turismo cultural “[...] por considerar em sua essência recursos audiovisuais intrínsecos à área da cultura” (BRASIL, 2010, p. 23).

Outro argumento que sustenta que a raiz desse segmento no turismo cultural é que "[...] os filmes, documentários, programas e seriados de TV funcionam como difusores da cultura, das paisagens e dos valores sociais das regiões e mesmo dos países onde foram produzidos" (BRASIL, 2007b, p.4). A relação que existe entre o turismo cultural e o cinematográfico é o fato dos turistas buscarem monumentos e locais culturalmente relevantes, enquanto que os turistas do segmento cinematográfico buscam também esses marcos, mas que os façam fazer a ligação entre o local e cena vista no filme (TANJA, 2012, p. 13).

O turismo cinematográfico é um segmento que lida diretamente com recursos audiovisuais, pois são esses recursos que originarão as produções audiovisuais que irãomotivar diversos turistas em suas viagens. Essas produções podem ser filmes, seriados de TV, novelas, entre 
outros. Para este artigo serão considerados esses três, principalmente as novelas, produto audiovisual amplamente consumido pelo mercado brasileiro.

Sabe-se que o audiovisual influencia espectadores a viajarem. Em 1998, os filmes vistos para além de objetos de diversão e discussão também induziam as pessoas a se deslocarem para conhecer as locações que foram vistas na tela de cinema (RILEY; BAKER; VAN DOREN, 1998, p.919). Porém, “[...] apenas recentemente esse segmento de negócios passou a ser amplamente explorado em várias regiões do mundo" (NASCIMENTO, 2009, p.12).

Dessa forma, o turismo cinematográfico constitui-se um segmento recente no mercado turístico, e ainda mais no meio acadêmico. É um segmento novo e uma área pouco examinada do turismo (TANJA, 2012, p. 14) e seu estudo encontra-se relativamente em seu início (HUDSON; RITCHIE, 2006). Em se tratando de definições, Nascimento (2009, p.12) argumenta que o termo cineturismoé utilizado pelos italianos, enquanto que os ingleses definiram como screentourism eos estadunidenses como movietourism. Todavia, todos os termos fazem referência a um segmento que se baseia na visitação às locações onde são produzidos filmes cinematográficos e séries televisivas.

Ainda nessa questão, o Ministério do Turismo desenvolveu em 2007 um estudo em parceria com o Instituto Dharma, cujo resultado foi uma produção intitulada "Estudo de sinergia e desenvolvimento entre as indústrias do turismo e audiovisual brasileiras" (BRASIL, 2007a) no qual são abordadas algumas questões fundamentais da relação existente entre o audiovisual e o turismo. Além disso, esse estudo apresenta uma série de estudos de caso do segmento, mostrando os benefícios que o turismo cinematográfico trouxe para alguns países. Traz também algumas orientações estratégicas para o desenvolvimento do segmento. Nesse estudo, está presente, ainda, uma cartilha com o título "Cartilha do turismo cinematográfico brasileiro", cujo principal objetivo é apresentar o segmento ao trade turístico, além de propor algumas orientações de seu desenvolvimento. Ainda na cartilha, encontram-se algumas definições básicas da temática de turismo e cinema, bem como a definição do seu tipo de turista. De acordo com a cartilha,

[...] o desejo do expectador de viver as emoções e de se transportar para os cenários retratados na tela grande é tanto que já existe até um segmento de turistas que viajam para as paisagens que servem de pano de fundo de filmes: são os chamados set-jetters (BRASIL, 2007b, p. 3). 
A definição apresentada pelo Ministério do Turismo traz consigo a classificação quanto aos turistas desse segmento, conhecidos como set-jetters. Nesse caso, os turistas viajam motivados a conhecer aqueles locais que eles viram em uma produção audiovisual, podendo ser filmes, seriados ou até mesmo as telenovelas, para o caso do Brasil.Nascimento (2009), conforme já mencionado, afirma que os set-jetters são fãs de filmes, programas de TV, mas inclui também os leitores de livros famosos e estes sujeitos viajam pelo planeta em busca das locações onde foram realizadas as produções literárias e audiovisuais. Com isso, a proposta principal do turismo cinematográfico é de levar os turistas aos locais onde foram filmados seus filmes prediletos.

Os turistas do segmento desejam fazer a ligação entre o real e o imaginário por meio dos locais reais que funcionam como ligações simbólicas entre o mundo real e o mundo imaginário (ROESCH, 2009 apudTANJA, 2012, p.14). Cabe ressaltar que a definição proposta aos turistas do segmento como set-jetters somente foi encontrada em publicações do Brasil, como a Cartilha do Ministério do Turismo e a obra Cineturismo (2009) do Nascimento, não sendo encontradas referências sobre esse termo em publicações de língua estrangeira. Para essas publicações internacionais, os turistas do segmento são designados apenascomo turistas cinematográficos.

Macionis (2004), por sua vez, apresenta uma definição de turismo induzido por filmes com base no momento da pós-modernidade no qual a atual sociedade se encontra. Ela afirma que:

[...] este novo nicho de turismo definido refere-se a uma experiência pósmoderna de um lugar que foi retratado em alguma forma de representação midiática. Ou seja, uma experiência altamente personalizada e única para cada indivíduo baseado em sua própria interpretação e consumo de imagens midiáticas" (MACIONIS, 2004, p. 87).

Beeton (2005, p.9) expande a definição incluindo na definição a televisão, vídeo e o DVD. A inclusão desses outros produtos na definição explica-se pelo fato do filme poder ser reproduzido e comercializado de diversas maneiras e em diversos canais, incluindo a TV, gerando um efeito em longo prazo da sua influência.

O turismo induzido por filmes engloba ainda, duas vertentes: o turismo induzido por filmes on-location e off-location. Segundo Beeton (2005, p. 43), o termo on-location é utilizado para especificar o turismo praticado em locais onde cenas particulares ou elementos de filmes e séries de TV são filmados. Seguindo o raciocínio, o termo off-location é proposto para o caso 
de atrações turísticas que são construídas para esse fim exclusivamente. Essas podem ser visitas guiadas em estúdios de filmagens de Hollywood ou então os parques temáticos com atrações de filmes como os parques da Universal em Orlando e na Califórnia ou os da Disney World, em Orlando e Disneyland em Anaheim, na Califórnia (EUA). A diferença primordial entre o on e off-location é que o primeiro se baseia em locais reais, preexistentes que não foram criados a partir de produções audiovisuais, enquanto que o segundo, são locais criados com uma proposta já delimitada para esse uso, ou seja, são estúdios com cenários e cidades cenográficas.

A Scotland'sNational Tourism Organisation define o film tourism (turismo cinematográfico, em tradução livre) como um ramo de negócios no qual os visitantes são atraídos para uma área através da história de um filme ou por meio da exposição de um determinado local num filme ou televisão, enquanto isso, turismo induzido por filmes é um termo amplo no qual os turistas viajam para um destino após tê-lo visto em uma tela antes (TANJA, 2012, p.14).

Ainda na questão da motivação, Macionis (2004) faz um estudo específico sobre a motivação dos turistas cinematográficos. Afirma que existem três tipos desses turistas: o turista cinematográfico por acaso, o turista cinematográfico geral e o turista cinematográfico específico. No primeiro caso são os turistas que, por acaso, estão num destino que foi exibido num filme, no segundo caso são turistas atraídos para um destino por causa de um filme, e que participam das atividades do segmento enquanto no destino, e por último, no terceiro caso são os turistas que procuram, ativamente, locais que eles viram em filmes. Para cada um dos casos existirão motivações específicas que irão atuar dentro do indivíduo de modo a fazer com que ele escolha um destino cinematográfico.

Finalmente, pode-se perceber a variedade de terminologias que existem para defini-lo, porém independentemente do termo que se utilize todos eles tem o mesmo objetivo: são adotados na definição de um segmento no qual os turistas são atraídos ou estimulados para um destino após tê-lo visto em alguma tela, seja ela a tela do cinema ou a tela da televisão de sua sala, por meio das mídias digitais compactadas (DVD/Blu-Ray), ou pela tendência mundial crescente, que é a exibição de conteúdo audiovisual em streaming, ou seja, por meio de sites e aplicativos que reproduzem filmes, séries, novelas, videoclipes e shows pela internet de acordo com o interesse do público ou ainda o sistema on demand, popularizado pelas operadoras de TV a cabo ou satélite que garantem acesso (mediante pagamento, na maioria dos conteúdos) de acordo com o interesse e tempo do cliente. 
Assim, independente da forma de visualização de produtos audiovisuais, destaca-se que no presente artigo o termo turismo cinematográfico será o adotado, pois se busca seguir um padrão apontado pelo próprio Ministério do Turismo no que se referem às segmentações turísticas e por acreditar que essa definição engloba todas as formas possíveis discutidas pelos autores.

É grande a discussão em torno dos conceitos sobre o turismo cinematográfico, mas é chegado um momento em que é preciso delimitar quais são os benefícios desse segmento para um destino turístico. Em linhas gerais são três os grandes principais benefícios: o primeiro deles é o fato dos filmes aumentarem a atenção do turista cinematográfico; aumento do apelo do destino; e finalmente, contribuição para a viabilidade do turismo no destino (RILEY; VAN DOREN, 1992, p. 269). Assim, esses três fatores estão interligados, ou seja, a partir do momento em que o turista tem sua atenção elevada em relação a um destino visto em um filme, automaticamente o destino passa a se tornar mais atraente para ele, e dessa forma a possibilidade do sujeito visitar os locais que serviram de cenários reais se torna maior, mais tangível. Além disso, os filmes podem reduzir problemas de sazonalidade, uma vez que a locação pode ser usada como atrativo ao longo do ano, em qualquer clima (BEETON, 2005). É valido também argumentar que mesmo na alta temporada o turismo cinematográfico pode ser pertinente, especialmente se as locações reais de uma cidade forem locais distantes dos atrativos turísticos tradicionais, gerando assim uma melhor distribuição dos fluxos turísticos na localidade visitada.

Outro aspecto positivo é o fato de tanto os filmes (cinema) como a televisão possuírem apelo socioeconômico mundial, aumentando potencialmente a base de visitantes (SCHOFIELD, 1996). Mesmo após o lançamento de um filme, o interesse pelos locais exibidos em uma produção audiovisual pode continuar motivando fluxos de turistas, tornando-o um segmento resistente (HUDSON; RITICHIE, 2006, p. 388). Porém, tudo depende de planejamento da destinação para se apropriar dessaexposição. Um fato observado por Riley; Van Doren (1992) é que após a exibição de um destino num filme, o número de turistas aumenta e, o mais interessante é que, mesmo com quedas de visitantes após um tempo, ele continuará com um número maior de visitantes ao momento anterior ao da exposição do destino num filme.

A publicidade e a propaganda estão em todos os lugares e momentos da vida do sujeito, estimulando o consumo de uma diversidade de produtos, incluindo os turísticos. É nesse sentindo que o marketing de cidades inova ao explorar em filmes a exposição de um destino 
turístico, pois ao visualizar uma localidade no filme, no conforto de uma sala de cinema ou em sua própria casa, o turista está livre de qualquer bloqueio, estando apto a experimentar as atrações sem a carga das publicidades tradicionais pagas e assim, poderá absorver a mensagem de maneira mais efetiva. As mensagens presentes nos filmes "[...] são memoráveis o suficiente para capturar a atenção e manter o interesse das pessoas que não podem viajar imediatamente" (RILEY; VAN DOREN, 1992, p. 267). As mensagens nesse caso, são os desejos que poderão aflorar após a visualização do destino num filme, e esse desejo pode perdurar no indivíduo por bastante tempo até que ele finalmente consiga atingir sua vontade e conhecer o local que ele outrora vira num filme.

\section{Niterói como Destino Cinematográfico}

Niterói é um dos 92 munícipios que compõem o Estado do Rio de Janeiro. Fundada em 1573, o município possui atualmente uma área de aproximadamente $134 \mathrm{mil} \mathrm{km}^{2}$ e uma população estimada em 494.200 habitantes, de acordo com os dados do IBGE (2013). Faz parte de Região Metropolitana do Rio de Janeiro e está localizado a $13 \mathrm{~km}$ da capital (NELTUR, 2011). Em termos de acesso, existe a possibilidade de entrada por meio da ponte Rio-Niterói, que interliga a cidadeao Rio de Janeiro por sistema de transporte rodoviário ou pelo sistema de transporte marítimo pela Baia de Guanabara, via barcas. Outro acesso é pelas cidades limítrofes: São Gonçalo e Maricá. Possui importância histórica desde o período de descoberta do país, chegando a ser capital do Estado da Guanabara até o ano de 1974.

Atualmente, no campo do turismo, o município faz parte da Região Turística Metropolitana no Estado do Rio de Janeiro que compreende além dele o município do Rio de Janeiro (NELTUR, 2011, p. 6) e é considerada um dos destinos indutores pelo Ministério do Turismo. Dessa forma, Niterói está localizada na região turística de maior relevância para o turismo nacional e internacional do país.

Possui uma oferta turística expressiva, devido ao fato da cidade ter tido um peso histórico para a região na qual ela se encontra. Além disso, possui o segundo maior conjunto arquitetônico projetado por Oscar Niemeyer, ficando atrás somente de Brasília. Segundo informações do site da Neltur, Niterói possui oito museus, oito praias da Baía e cinco praias oceânicas, possui cinco fortes e uma fortaleza, cinco parques, sendo um deles, um parque 
estadual e 14 igrejas históricas. Possui ainda, teatros, cinemas, ateliês, bibliotecas, centros culturais, galerias de arte e diversas outras opções de lazer espalhadas pela cidade.

Tratando-se das produções audiovisuais, Niterói já serve como locação para produções diversas, majoritariamente produções da Rede Globo que é responsável pelo maior número de produções rodadas na cidade, entre novelas e minisséries, além de coproduções de filmes e documentários. Dessas produções, destaca-se a novela "Beleza Pura" (2008), na qual Niterói e suas belezas foram destaque em diversos momentos da novela, pois os protagonistas eram da cidade. Nessa novela foram feitas cenas no MAC de Niterói, na estação hidroviária de Charitas, no Solar do Jambeiro, transformado em orfanato, no Museu do Ingá, transformado em escola, além de cenas aéreas da cidade. A fachada de um hospital oftalmológico também foi utilizada durante as gravações e na novela assumia o papel de uma clínica de estética. Outra produção que teve Niterói como locação foi a minissérie "As Brasileiras" (2012), que destinou um episódio inteiro dedicado à cidade. Entretanto, apenas algumas cenas foram rodadas na estação hidroviária de Charitas, sendo que a maior parte das cenas era aérea, mostrando sobrevoo sobre os principais pontos turísticos, como o Parque da Cidade, o MAC de Niterói e as principais praias da baía.

Recentemente, a cidade também foi destaque em um filme nacional de grande repercussão e sucesso: "Minha mãe é uma peça" (2013). O filme teve cenas rodadas em alguns locais até então não mostrados em outras produções, como o Campo de São Bento e a orla da Praia de Icaraí. Além desses locais, os atrativos mais conhecidos da cidade também foram mostrados em cenas aéreas.

A novela "Lado a Lado" (2012) também teve cenas rodadas em Niterói, no Teatro Municipal João Caetano, onde foi feita uma apresentação musical do início do século XX e a novela "Escrito nas Estrelas" (2010) gravou uma cena de apresentação de teatro no local. Uma cena do filme "Tropa de Elite 2" (2010) foi gravada em uma rua da cidade. O estacionamento da empresa de energia elétrica da cidade e a rua que dá acesso a esse estacionamento foram usados para a gravação de uma cena de tiroteio entre os personagens do filme. O filme "Nosso Lar" (2010) gravou diversas cenas do hospital nas instalações da Fortaleza Santa Cruz e outras no MAC, a novela “Amor a Vida" (2009) gravou algumas cenas no MAC, na qual uma personagem fazia um ensaio fotográfico na rampa que dá acesso ao museu. Na Fortaleza Santa Cruz também foram rodadas cenas do filme “A Casa da Mãe Joana 2” (2013). 
Houve gravação de uma cena de acidente de carro dentro do túnel que liga os bairros de Icaraí e São Francisco para a novela "Amor Eterno Amor" (2012). Em 2010, a novela "Avenida Brasil" gravou algumas cenas na praia de Itacoatiara e seu entorno. Na cena foi retratada uma festa que acontecia em algum local próximo a praia e, posteriormente, uma das personagens saia dessa festa pela praia de Itacoatiara. A novela "Salve Jorge" (2012) gravou uma cena no Solar do Jambeiro, onde uma das salas do palacete foi transformada em um leilão turco e também rodou algumas cenas na praia de Itacoatiara.Houve ainda a novela "Joia Rara" (2013) que teve algumas cenas gravadas nos Fortes do Pico e São Luís.

É perceptívelque a cidade de Niterói já possui alguma expressão em termos de produção audiovisual que ocorreram na cidade e foram responsáveis em aumentar a exposição dela na mídia. Acredita-se que sua atuação dentro do segmento de turismo cinematográfico não é expressiva, uma vez que a produção audiovisual da cidade ainda é pequena e somando-se a esse fato, não é possível quantificar a existência de turistas do segmento na cidade pela carência de pesquisas de demanda que identifiquem esse perfil. É válido destacar que durante as pesquisas e contatos com a NELTUR, as informações das produções audiovisuais atreladas ao turismo não são aproveitadas para promoção turística do município, não há no site e nem nos prospectos de turismo da prefeitura qualquer menção ou potencial para desenvolvimento do turismo cinematográfico.

\section{A Construção do Catálogo}

A pesquisa começou a partir de um levantamento prévio feito no site da Neltur, onde foram encontrados todos os atrativos da oferta da cidade. Em seguida, o mesmo levantamento foi realizado no site da Rio Film Commission (RFC), sendo que somente as informações que não constavam no site da Neltur foram incluídas no levantamento final. Como critério de definição para a entrada dos locais no catálogo, definiu-se que, de todos os atrativos levantados, constariam na lista somente os que foram abordados numa pesquisa realizada pelo curso de Bacharelado em Turismo da UFF e Neltur, em 2011. Essa pesquisa teve como principal objetivo a caracterização do fluxo e da demanda turística do destino Niterói (NELTUR, 2011), identificando o perfil do turista que visita a cidade. Portanto, é entendido que os atrativos citados pelos turistas na pesquisa são aqueles que retratam a identidade da cidade, portanto, os atrativos de maior potencial para o segmento estudado. 
Sendo assim, os atrativos que constam no catálogo são: os edifícios do Caminho Niemeyer (Teatro Popular, o Museu Oscar Niemeyer, o Memorial Roberto Silveira/ Centro da Memória da História e da Literatura Fluminense, Centro de Atendimento ao Turista (CAT), Praça JK, Centro Petrobrás de Cinema e o Museu de Arte Contemporânea (MAC), com destaque para o Teatro Popular e o MAC, a estação hidroviária de Charitas, o Museu do Ingá, o Arqueológico de Itaipu e o Museu Janete Costa de Arte Popular, o complexo de Fortes da cidade, com destaque para a Fortaleza Santa Cruz, as praias da baia e oceânicas, o Parque da Cidade, o Parque Estadual Serra da Tiririca, os polos gastronômicos, o Solar do Jambeiro, o Teatro Municipal, o Campo de São Bento e o Mercado São Pedro.

Nas figuras a seguir, há uma exemplificação do catálogo de atrativos turísticos e potenciais locações de Niterói, contendo seus referidos nomes, imagens, características e informações geraisque entraram no produto final, fruto do catálogo completo produzido por Oliveira (2014), com a monografia intitulada "Luz, Câmera... Segmentação: uma proposta de turismo cinematográfico para a cidade de Niterói - RJ", apresentada para o Departamento de Turismo da Faculdade de Turismo e Hotelaria da Universidade Federal Fluminense como requisito final de avaliação do curso de Turismo.

Assim, tendo em vista apresentar alguns dos atrativos turísticos relevantes da cidade para destacá-los como lugar com forte potencial para servir de locação às produções audiovisuais no município optou-se por separar os atrativos culturais (figura 1) dos atrativos naturais (figura 2). É válido ressaltar que no trabalho monográfico foram levantados 37 atrativos culturais e 17 atrativos naturais, com isso, trabalhamos com uma amostra de $18 \%$ dos atrativos que foram inventariados com a finalidade de destacar a relação intrínseca entre o potencial turístico e as locações para produções audiovisuais.

Os atrativos culturais selecionados são bens edificados com grande relevância por compor uma amostra do patrimônio cultural niteroiense, além de expor antigos palacetes como os edifícios do Solar do Jambeiro e Museu do Ingá, incluiu-se a Fortaleza de Santa Cruz da Barra com excelente vista para a cidade do Rio de Janeiro. Houve a inclusão do Museu de Arte Contemporânea e do Teatro Popular, ambos projetados pelo arquiteto Oscar Niemeyer. 


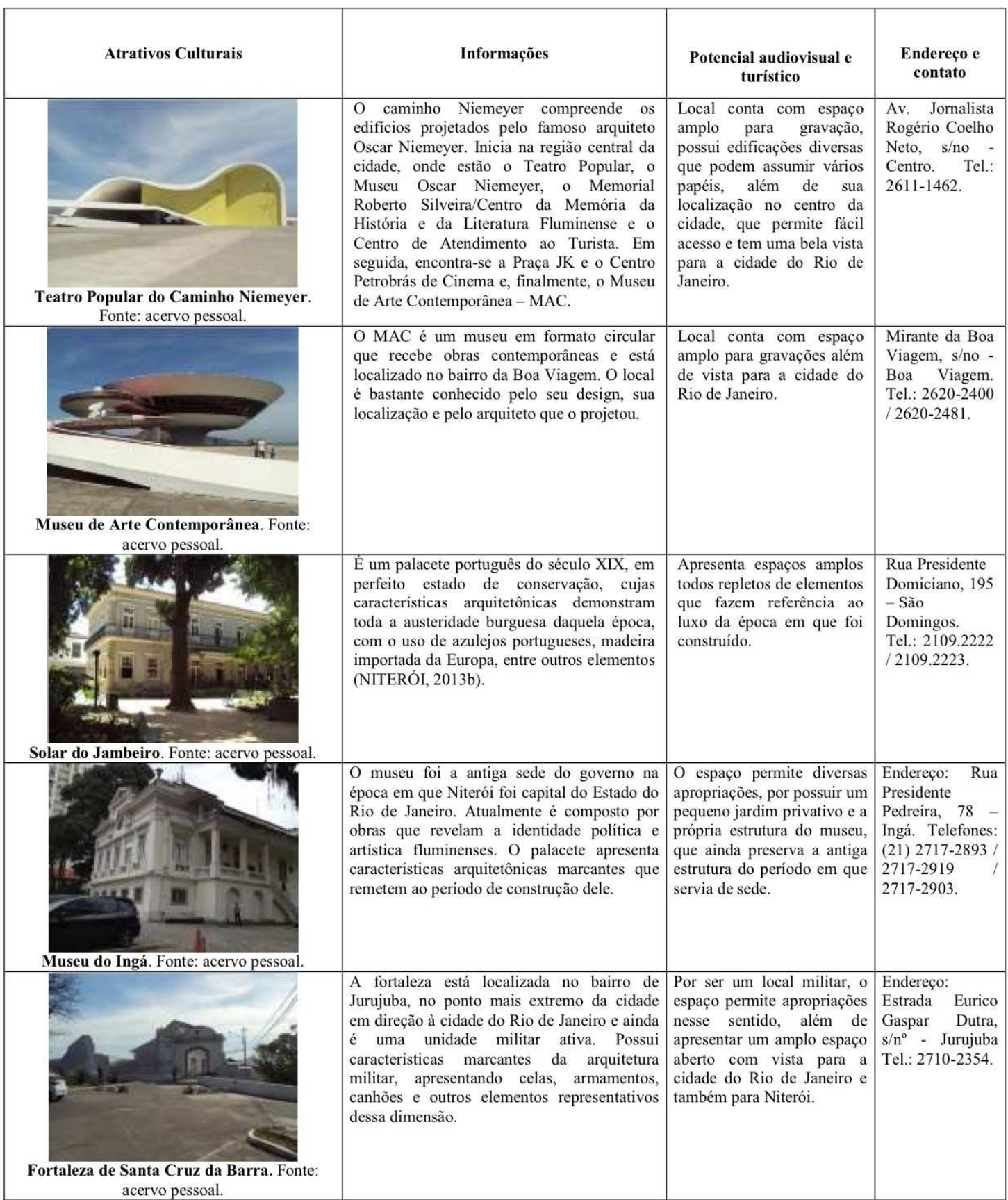

Figura 1: Amostra de atrativos culturais com suas respectivas informações que serviram para compor o catálogo de locações a partir dos atrativos turísticos de Niterói.

Fonte: Elaboração própria.

Os atrativos naturais selecionados para essa amostragem são predominantemente as praias do município, com destaque para a Praia de Icaraí, Itaipu, do Sossego e da Boa Viagem. Foi incluído também o Parque Estadual Serra da Tiririca, sendo este uma Unidade de Conservação com expressiva variedade de fauna e flora nativas e presença de comunidade 
tradicional. Os atrativos naturais em questão, possuem vistas para paisagens naturais com marcante geomorfologia e visão privilegiada para a cidade do Rio de Janeiro.

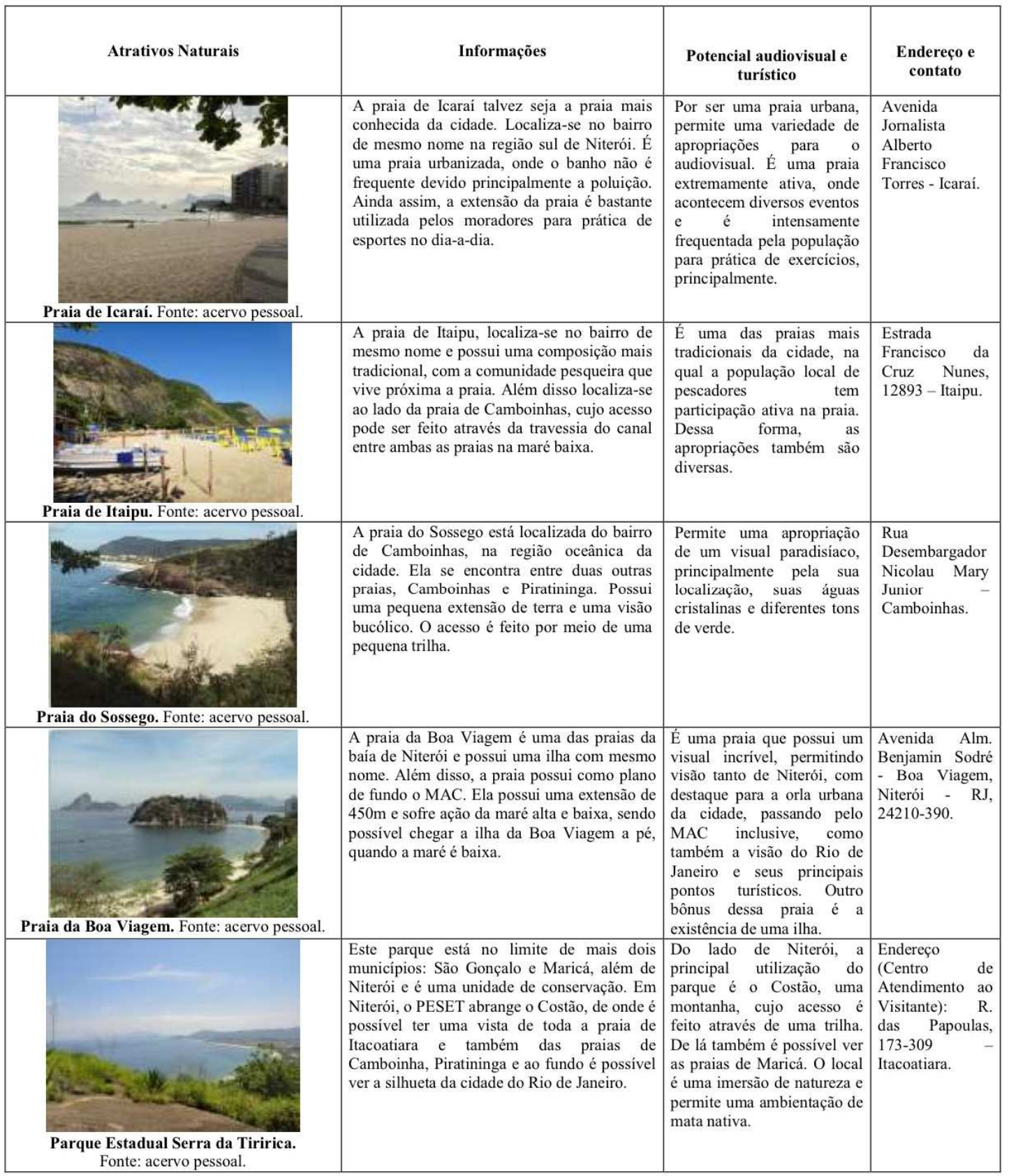

Figura 2: Amostra de atrativos naturais com suas respectivas informações que serviram para compor o catálogo de locações a partir dos atrativos turísticos de Niterói.

Fonte: Elaboração própria. 
Vale ressaltar que todos os locais foram $\operatorname{visitados}^{3}$, fotografados e informações referentes ao contato e endereço foram levantadas. Além disso, algumas informações históricas de alguns desses atrativos e proposições de possíveis apropriações que esses locais poderiam servir para produções audiovisuais para constar no catálogo final de locações da cidade de Niterói são descritas no catálogo.

Contudo, a construção desse catálogo representou um importante passo no desenvolvimento do turismo cinematográfico em Niterói. Nele estão os atrativos que reproduzem a identidade da cidade e suas possíveis apropriações para produções audiovisuais. Além disso, sua própria existência e construção evidenciam o seu potencial para o segmento em questão e visa sair da sombra da cidade do Rio de Janeiro, mesmo que esta esteja presente no horizonte da vista a partir de Niterói, porém, tendo a identificação do município e não o entendimento como uma mera extensão da cidade carioca. Desta forma, utilização do catálogo como um produto divulgador orientará produtores e cineastas com intuito de captar novas produções para cidade, ampliando inclusive o catálogo de locações de Niterói, existente na página da Rio Film Commission $(\text { RFC })^{4}$.

\section{Considerações Finais}

Entendendo a segmentação turística como um novo caminho de desenvolvimento do turismo mundial, percebe-se o turismo cinematográfico como um segmento recente que está em expansão em diversos países. A principal discussão que permeia esse segmento está relacionada à motivação desses turistas em conhecer novos destinos. Diferentemente da maioria dos turistas, os set-jetters são motivados a conhecer destinos por meio da exposição desses locais em produções audiovisuais, tais como: filmes, minisséries, as novelas e outros, aproximando da realidade brasileira.

Alguns benefícios podem ser percebidos a partir dessa exposição de atrativos por meio de produções audiovisuais, como por exemplo, a possibilidade de diversificação do interesse do

\footnotetext{
${ }^{3}$ Locais nos quais foram feitos contato presencial e por email: Fortaleza de Santa Cruz da Barra, Solar do Jambeiro, Forte São Luis e do Pico, Caminho Niemeyer, o Museu Janete Costa de Arte Popular, o Museu do Ingá e o Parque Estadual Serra da Tiririca (PESET). O registro das imagens foi feito em setembro de 2013.

${ }^{4}$ No endereço eletrônico da Rio Film Commission é possível hoje encontrar 14 locações. Essa ampliação é recente, tendo em vista que no ano de 2013, quando foi iniciada a pesquisa referente às locações, constavam apenas três. Disponível em: http://www.riofilmcommission.com/all-locations. Acesso em: 12 nov. 2015.
} 
fluxo turístico na alta ou baixa temporada, tendo em vista que os turistas cinematográficos vão buscar a identificação das locações e atrativos turísticos exibidos em filmes, séries, novelas e outras, fazendo com que haja um turismo pautado no audiovisual.

Voltando à questão problema deste artigo, pode-se afirmar que, com base nos resultados obtidos, a cidade de Niterói possui capacidade em diversificar o seu turismo a partir da formatação do turismo audiovisual e cinematográfico, sustentado pela variedade de atrativos que podem ser usados como locação na cidade, pelas produções que já ocorreram em diversos desses atrativos, algumas de grande expressão na mídia e, finalmente, pela construção do catálogo de locações da cidade, que servirá de apoio a futuras produções.

Dessa forma, a cidade pode oferecer um novo segmento ao mercado, atraindo turistas, dando a possibilidade de sair do tradicional turismo de sol e praia ou de negócios ou de eventos. Associado a este fato, o desenvolvimento do segmento na cidade, poderá gerar fluxo turístico na baixa temporada, auxiliando possíveis problemas de sazonalidade. Outro ponto relevante é o fato do turismo cinematográfico trazer benefícios antes mesmo da vinda dos set-jetters, com a utilização dos serviços básicos e turísticos por parte da equipe de produção que estiver filmando na cidade durante o processo de produção e também a possibilidade de criação de postos de trabalho para a comunidade local em virtude da necessidade da produção, que pode precisar de mão-de-obra local para algum trabalho específico.

Todavia, para alcançar o desenvolvimento desse segmento é preciso que sejam feitas produções audiovisuais na cidade, de modo a projetar a imagem dela para um público maior. Uma boa maneira de conseguir captar produções audiovisuais é pela criação de incentivos fiscais associadas a outras ferramentas de grande relevância, sendo este o papel representado pela Secretaria de Cultura do governo do estado por meio da Rio FilmCommission. O catálogo de locações é considerado como uma dessas ferramentas de importância para a captação de destinos, pois é nele que irão constar os locais passíveis de apropriação para filmagem que são, muitas vezes, os atrativos turísticos da cidade.

Sabendo-se que a cidade de Niterói ainda não possui um catálogo próprio e completo de locações que exponha toda sua potencialidade para produção audiovisual, buscou-se catalogar os atrativos da cidade que expressassem a identidade da cidade, junto com possibilidades de apropriação deles para produções. Foram criados então, dois de catálogos contendo atrativos já reconhecidos pelos turistas e outros com potencial. Nesses catálogos foram levantadas 
informações básicas a respeito da localização desses atrativos, fotos, descrições, algumas possibilidades de uso audiovisual e, em alguns casos, foram elencadas produções que já tenham ocorrido nesses locais.

É importante ressaltar que alguns problemas foram encontrados durante o processo de construção desses catálogos, sendo o primeiro deles a falta de informações confiáveis e a dificuldade de se obter as informações junto ao órgão oficial responsável pelo segmento do audiovisual no Rio de Janeiro (a Rio Film Commission). Ainda assim, a construção dos catálogos foi importante, pois se apresenta como uma documentação importante para o segmento, ao facilitar a exposição dos atrativos para futuras ofertas de produção na cidade, aumentando então cada vez mais a transmissão da imagem de Niterói pelo imaginário das pessoas, para finalmente, gerar fluxo turístico para a cidade.

Como sugestão, fica o apelo para que novas pesquisas acadêmicas no segmento sejam desenvolvidas, principalmente na área de demanda turística, identificando os turistas cinematográficos na cidade e região metropolitana do Rio de Janeiro. Os resultados obtidos nessas pesquisas irão auxiliar no melhor planejamento do segmento, bem como o direcionamento e a apresentação dos atrativos a partir das produções já gravadas nas locações visitadas. Igualmente, os catálogos de locações são apenas um modelo e está aberto a adaptações e melhorias, sempre que essas forem necessárias. Ainda nesse sentido, o fomento de uma Film Commission para a cidade de Niterói também pode ser entendido como uma alternativa interessante no desenvolvimento do audiovisual na cidade, juntamente com parcerias, como por exemplo, com o curso de Cinema e com o de Turismo da Universidade Federal Fluminense.Assim, espera-se expandir os níveis de conhecimento dessa área que ainda é tão pouco estudada no país.

\section{Referências}

BEETON, S. Film induced tourism. Clevedon: Channel View Publications, 2005.

BRASIL. MINISTÉRIO DO TURISMO. Estudo de sinergia e desenvolvimento entre as indústrias do turismo e audiovisual brasileiras.Brasília, 2007a. MINISTÉRIO DO TURISMO. Turismo cinematográfico brasileiro.Brasília, 2007. . MINISTÉRIO DO TURISMO. Turismo cultural: orientações básicas. $3^{\mathrm{a}}$ ed. Brasília, 2010.

CONNELL, J. Film tourism - evaluation, progress and prospects.Tourism Management, vol. 33, pp. 1007-1029, 2012. 
DENKER, A. de F. M. Pesquisa em turismo: planejamento, métodos e técnicas. São Paulo: Futura, 1998.

FONSECA FILHO, A. da S. Educação turística - formação contínua de professores da educação básica para o ensino do turismo. 2013. 268 f. Tese (Doutorado) - Faculdade de Educação, Universidade de São Paulo, São Paulo, 2013.

HUDSON, S.; RITCHIE, J.R.B. Promoting destinations via film tourism: an empirical identification of supporting marketing initiatives. Journal of Travel Research, vol. 44, 387-396, Maio, 2006.

INSTITUTO BRASILEIRO DE GEOGRAFIA E ESTATÍSTICA (IBGE). IBGE cidades. Disponível em: 〈http://cidades.ibge.gov.br/xtras/perfil.php?lang=\&codmun=330330>Acesso em: 19 out. 2013.

KOTLER, P. Administração de Marketing.10 ed. São Paulo: Prentice Hall, 2000.

MACIONIS, N. Understanding the film induced tourists.In: Proceedings of the International Tourism and Media Conference. Melbourne, Australia: Tourism Research Unit, Monash University, 2004, p. $86-97$.

NASCIMENTO, F. M. e. Cineturismo. São Paulo: Aleph, 2009.

NITERÓI EMPRESA DE LAZER E TURISMO (NELTUR).Pesquisa de demanda turística do município de Niterói (RJ) - nacional e internacional ano de 2011. Niterói, 2011.

Solar do Jambeiro: descrição arquitetônica. Disponível em:

<http://culturaniteroi.com.br/blog/?id=188> Acesso em: 10 set. 2013.

OLIVEIRA, R. D. S. de. Luz, câmera...segmentação! Uma proposta de turismo cinematográfico para a cidade de Niterói - RJ. 2014. 86f. Monografia (Graduação) - Faculdade de Turismo, Universidade Federal Fluminense, Rio de Janeiro, 2014.

RILEY, R.; BAKER, D.; VAN DOREN, C. S. Movie induced tourism.Annals of Tourism Research, vol. 25, n. 4, p. 919-935, 1998.

.; VAN DOREN, C. S. Movies as tourism promotion: a pull factor in a push location. Tourism Management, vol. 13, n. 3, p. 267-274, 1992.

ROESCH, S. The experiences of film location tourists. Bristol: Channel View Publications, 2009.

SCHOFIELD, P. Cinematographic images of a city.Tourism Management, vol. 17, n.5, p. 333-340, 1996.

TANJA, T. Film tourism: study on how films can be used to promote tourism. Laurea University of Applied Sciences, 2012.

\section{Recebido em: 01/12/2015 (1 ${ }^{\mathrm{a}}$ versão $)$ 19/05/2016 ( $2^{\mathrm{a}}$ versão)}

Aprovado em: 21/06/2016 